\title{
FLEXIBILIZAÇÃO DAS LEIS TRABALHISTAS: OS ENTRAVES E DESAFIOS CONSTITUCIONAIS
}

\section{FLEXIBILIZATION OF LABOR LAWS: CONSTITUTIONAL BARRIERS AND CHALLENGES}

Abnoan Reis Santos Junior ${ }^{1}$, Lucas Monteiro Mendes Batista ${ }^{2}$, Marcus Vinicius do Nascimento Lima ${ }^{3}$

Submetido em: 29/04/2021

e24285 Aprovado em: 19/05/2021

\section{RESUMO}

Diante do contexto de constantes mudanças em que se encontra o Direito do Trabalho no Brasil, visando, sobretudo acompanhar a dinâmica do mercado de trabalho, desponta como um dos institutos mais discutidos nesse ramo da ciência jurídica a flexibilização da legislação trabalhista. Isso decorre principalmente do impacto que esse instituto possui, vez que extrapola o âmbito das relações entre empregador e empregado e se faz relevante diante das relações econômicas e sociais em geral. Apesar de ser um reflexo da constante mutação a qual está submetida o Direito Trabalhista, há necessidade de resguardar certas garantias trabalhistas conquistadas ao longo de toda evolução histórica das normas laborais. Nesse sentido, o presente estudo procura, através da pesquisa bibliográfica e documental utilizando-se da análise da doutrina e da legislação pátria, com a utilização do método dedutivo, estabelecer quais as principais limitações que o instituto da flexibilização das leis trabalhistas encontra diante da tutela conferida à figura do trabalhador pela norma constitucional brasileira.

PALAVRAS-CHAVE: Flexibilização. Leis Trabalhistas. Limites Constitucionais.

\begin{abstract}
Given the context of constant changes in which the Labour Law in Brazil is found, aiming, above everything, accompany the dynamics of the labor market, the flexibilization of labor laws emerge as one of the most discussed institute in this branch of legal science. This is due to the impact that this institute has, since it goes beyond the scope of relations between employer and employees and becomes relevant even in general economic and social relations. Despite being a reflection of the constant mutation in which Labor Law is subjected, there is a need to safeguard certain labor guarantees achieved throughout the entire historical evolution of labor standards. In that regard, the present study seeks, through bibliographic and documentary research using the analysis of the doctrine and national legislation, with the use of deductive method, to establish what are the main limitations that the institute of flexibilization of labor laws finds facing the protection given to the figure of the worker by the Brazilian Constitutional norm.
\end{abstract}

KEYWORDS: Flexibilization. Labor Laws. Constitutional Limits.

\footnotetext{
1 Acadêmico do Curso de Bacharel em Direito do Centro Universitário Santo Agostinho. Estagiário na Defensoria Pública do Estado do Piauí.

2 Acadêmico do Curso de Bacharel em Direito do Centro Universitário Santo Agostinho. Estagiário na Defensoria Pública do Estado do Piauí.

3 Professor do Curso de Direito do Centro Universitário Santo Agostinho- UNIFSA. Mestre em Direito Constitucional pela Universidade Federal do Rio Grande do Norte - UFRN.
} 


\section{RECIMA21 - REVISTA CIENTÍFICA MULTIDISCIPLINAR ISSN 2675-6218}

FLEXIBILIZAÇÃO DAS LEIS TRABALHISTAS: OS ENTRAVES E DESAFIOS CONSTITUCIONAIS Abnoan Reis Santos Junior, Lucas Monteiro Mendes Batista, Marcus Vinicius do Nascimento Lima

\section{INTRODUÇÃO}

As intermitentes alterações nas conjunturas social política e econômica contemporâneas inevitavelmente acabam pressionando as normas jurídicas, que necessitam constantemente sofrer alterações com o objetivo de se amoldar da melhor forma possível aos novos paradigmas impostos pela complexa dinâmica que rege a vida em sociedade.

O modelo de sistema econômico capitalista atual exige cada vez mais competitividade e eficiência das empresas frente ao mercado interno e externo, essas por sua vez, necessitam buscar cada vez mais formas de aumentar sua produtividade, frequentemente inovando nos tipos de relação para com o trabalhador numa busca por formas de diminuir os gastos da atividade $e$ com o objetivo de conseguirem se manter lucrativas no mercado no longo prazo.

Dessa maneira, o sistema capitalista ao priorizar a redução de custos, competitividade, neutralização de conflitos e flexibilização, acaba por promover profundas mudanças no meio laboral. Dentre essas, destaca-se a redefinição do perfil de trabalhador, no lugar da tradicional subordinação jurídica, o trabalhador contemporâneo é chamado a assumir novos riscos, outrora vistos como responsabilidade exclusiva dos empregadores (MARTINEZ, 2019).

É diante desse contexto que o direito trabalhista notoriamente figura como uma das áreas do direito mais suscetíveis de sofrer alterações e flexibilizações em seus diplomas legais, vez que diante das novas formas de se estabelecerem relações trabalhistas não raramente encontram-se muitos entraves em uma legislação produzida para se adequar aos anseios da classe trabalhista do século passado.

Assim, observa-se no Brasil, desde a década de 1990, mas especialmente nos últimos anos, uma crescente influência da tendência mundial pela promoção de flexibilizações das leis trabalhistas, não apenas visando promover uma maior competitividade empresarial tanto no cenário exterior, como interior, mas também ancoradas na premissa de combater os problemas do desemprego e da informalidade.

Para reafirmar tal entendimento é válido lembrar que a transição democrática ocorrida no Brasil por volta de 1990 trouxe consigo uma verdadeira crise cultural, caracterizada entre outras pelas linhas de pensamento que propunham um menor grau de intervenção estatal, inclusive através dos instrumentos normativos, na economia e sociedade, essa vertente, ao defender a desregulamentação das relações de trabalho, foi uma das responsáveis pela acentuação do movimento de flexibilização observado, principalmente, na legislação trabalhista (DELGADO, 2017).

No entanto, apesar de ser inegável a importância de criar leis mais maleáveis frente às novas tendências que cercam as relações de trabalho, há que se atentar para os limites que tais flexibilizações acabam encontrando. Tais limites visam, principalmente, resguardar os direitos e garantias fundamentais conquistados pelos trabalhadores ao longo de um árduo e turbulento processo histórico. 


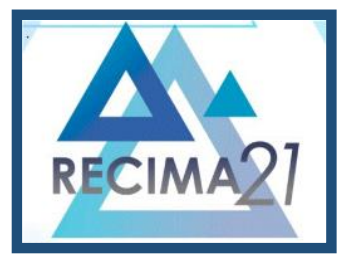

\section{RECIMA21 - REVISTA CIENTÍFICA MULTIDISCIPLINAR ISSN 2675-6218}

Embora seja evidente que essas adaptações nas leis trabalhistas não se apresentam como uma novidade na ordem jurídica brasileira, visto que algumas formas de flexibilizações são previstas até mesmo na Constituição Federal de 1988, é impreterível considerar que o próprio texto constitucional tratou impor as restrições a serem observadas ao promover novas alterações legais. Importante inclusive consignar que o texto constitucional tratou de reconhecer em seu art. $1^{\circ}$, inciso IV, o valor social do trabalho como um dos fundamentos da República além de conferir especial proteção aos direitos sociais estabelecidos no art. 6으 bem como notadamente prever um conjunto de direitos mínimos aos trabalhadores em seu art. 7ํ (MARTINEZ, 2019).

Tendo em vista o cenário exposto, e a partir do reconhecimento do trabalho como sendo uma das principais relações humanas, o presente estudo foi desenvolvido através da pesquisa bibliográfica e documental, utilizando o método dedutivo, com objetivo de analisar quais são as principais barreiras e desafios impostos pela Constituição Federal de 1988, no sentido de resguardar a figura do trabalhador, tido como o polo hipossuficiente da relação trabalhista, frente às propostas de flexibilizações que recaem sobre a legislação trabalhistas brasileira, e por consequência, na tutela estatal que incide sobre as relações trabalhistas.

\section{A EVOLUÇÃo HISTÓRICA DO DIREITO DO TRABALHO E DA LEGISLAÇÃO TRABALHISTA BRASILEIRA}

Antes de se falar em Direito do Trabalho, primariamente se deve compreender em que consiste o próprio Trabalho em si, assim como todas as fases que esse veio a atravessar juntamente com suas relações.

A termo de início, se faz imprescindível o conhecimento acerca do conceito de trabalho. Segundo Martins Rolar (2018), o Trabalho pode ser definido como todo atividade praticada pelo ser humano, no intuito de prover sua subsistência assim como da sua família, bem como buscar riquezas. O fenômeno do trabalho e suas relações passaram por diversas modificações ao decorrer dos tempos. Por sua vez, tal fenômeno tem sua existência desde os primórdios, e sua evolução, apesar dos momentos históricos mundialmente não serem unânimes, pode ser dividida em fases, isto é, regimes, que conduziam as formas em que se dava o trabalho.

Segundo Bezerra Leite (2019), as fases históricas do trabalho podem ser demarcadas em cinco diferentes regimes: primitivo, escravo, feudal, capitalista e por último comunista. No entanto, vale citar que entre os tempos de regime primitivo ao regime feudal não havia o que se falar em direito do trabalho, haja vista que nesses regimes, não havia um conjunto de normas destinadas a proteção do trabalhador, sendo o Direito do Trabalho basicamente inexistente. No regime primitivo o homem trabalhava apenas para prover sua subsistência e de sua família sem nem sequer saber do termo trabalho; no escravo, o trabalho era tido como pena, sendo o escravo tido como mero objeto, posse do seu dono; no regime feudal, o que se tinha, assim como na escravidão, era o 


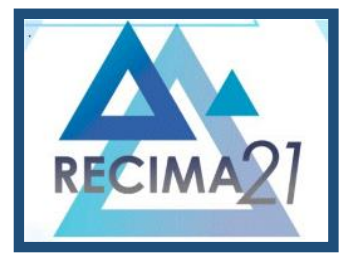

\section{RECIMA21 - REVISTA CIENTÍFICA MULTIDISCIPLINAR ISSN 2675-6218}

trabalho como castigo, usado como "moeda de troca" para conseguir proteção dos senhores feudais.

Tempos a frente, com a e evolução do comércio, e, por conseguinte a extinção da sociedade feudal, houve grande fomento da produção artesanais de bens, surgindo os chamados artesões profissionais. Com a finalidade de assegurar algumas prerrogativas culturas surgiam ali as associações profissionais, chamadas de corporações de ofício. No entanto, a liberdade do trabalho ainda era restrita, vez que, tais corporações tinham suas estruturas fundadas no controle exercido pelo mestre sobre os trabalhadores subordinados.

O trabalho livre passou a existir apenas com o advento da Revolução Francesa, haja vista que esta, trazia os princípios jurídicos elencados ao liberalismo, em especial, destaca-se o princípio da autonomia da vontade, trazendo, por conseguinte a liberdade de contratar. Com isso, grande transformação foi ocasionada nas relações de trabalho até aquele momento existentes, mudando o cenário conhecido.

Ademais, o que poderíamos chamar de Direito do Trabalho, assim como a Legislação Trabalhista passaram a existir apenas muito tempo após o próprio trabalho, tendo sua existência grande vínculo com o advento da Revolução industrial (acontecida na Inglaterra em meados do século XVIII) e da Revolução Francesa (acontecida na França, também no século XVIII). Assim sendo, apenas em tal período histórico pode-se começar a falar em Direito do Trabalho, vez que ali se iniciava seu surgimento. Acerca disso, trazem as precisas lições de Bezerra Leite (2019, p.40, grifo do autor):

\footnotetext{
No período histórico propriamente dito é que surge o direito do trabalho. Três foram as principais causas: econômica (revolução industrial), política (transformação do Estado Liberal - Revolução Francesa - em Estado Social intervenção estatal na autonomia dos sujeitos da relação de emprego) e jurídica (justa reivindicação dos trabalhadores no sentido de se implantar um sistema de direito destinado à proteção, como o direito de união, do qual resultou 0 sindicalismo, o direito de contratação individual e coletiva). Somando-se a essas causas, contribuíram decisivamente para o surgimento do direito do trabalho a ideia da justiça social preconizada, principalmente, pela Igreja Católica, através das Encíclicas Rerum Novarum e Laborem Exercens, e o marxismo, preconizando a união do proletariado e a ascensão dos trabalhadores, pela luta de classes, ao poder político.
}

Diante do regime jurídico que surgiu, entrelaçado totalmente aos ideais da revolução francesa (conceitos de liberdade e igualdade), e em consequência da Revolução Industrial, foi ocasionado um cenário de grande injustiça social, onde prevalecia enorme desigualdade econômica entre as partes que compunham a relação de trabalho. Diante disso, o Estado percebeu que não poderia continuar inerte e deixar desregulamentadas as relações de trabalho, vindo a estabelecer condições mínimas de proteção que deveriam ser respeitadas e seguidas pelos empregadores (parte mais forte da relação trabalhista). 


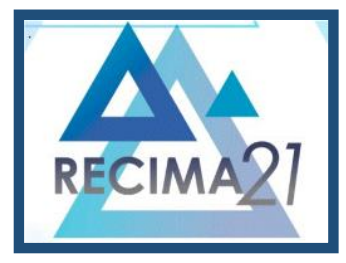

\section{RECIMA21 - REVISTA CIENTÍFICA MULTIDISCIPLINAR ISSN 2675-6218}

Ponto de grande importância para o direito do trabalho também ocorreu no ano de 1919, quando foi editado o Tratado de Versalhes, que traria previsão da criação da Organização Mundial do Trabalho - OIT, tendo como função universalizar as normas que protegeriam o trabalho humano. Destaca-se ainda que o Brasil é um dos Estados-membros fundadores da OIT, tendo sua participação na conferência internacional do trabalho desde a primeira edição.

Tratando especificamente do direito do trabalho no Brasil, destaca-se que esse tem como objeto o trabalho prestado de modo subordinado sendo possível a sua demarcação histórica em três fases distintas, conforme Bezerra Leite (2019): primeiro se tem a fase do descobrimento à abolição da escravatura; logo após, pode-se citar o período da Proclamação da República à campanha política da Aliança Liberal; e por último, a terceira fase vai da revolução de trinta aos dias contemporâneos.

O direito do trabalho brasileiro foi influenciado por ambos os fatores internos e externos. Como fator externo pode-se citar todas as transformações que ocorriam na Europa, bem como o já citado ingresso do país na OIT; como fator interno temos o movimento operário no final dos 1800 , o surto industrial e a política de Vargas.

Por outro lado, de grande relevância para o direito trabalhista brasileiro também merecem citação: as ligas operarias e, por conseguinte tem-se o início do sindicalismo pátrio em 1870, no ano de 1891, houve a proibição do trabalho noturno para menores de quinze anos e a Lei Elói Chaves, que por sua vez cria uma caixa de aposentadoria bem como a estabilidade dos ferroviários, sendo considerada por muito a primeira lei com caráter realmente trabalhista em terras brasileira. Soma-se a isso, a criação, no ano de 1925, da lei que disciplinava a férias anuais remuneradas, e em 1935, houve o advento da lei que assegurava aos empregados industriais e do comercio o recebimento de indenização em caso de rescisão contratual trabalhista sem justificativa e o direito a instabilidade para esses.

Contudo, apenas no ano de 1939, foi devidamente criada a chamada Justiça do Trabalho no Brasil. E somente no ano 1943, basicamente quatro anos após a criação da Justiça do Trabalho, foi outorgada por Vargas a Consolidação das Leis do Trabalho.

Além de que, acerca das constituições brasileiras merecem citações em termos de direito do trabalho, as cartas de 1934, 1937, 1946, 1967 e, em especial, a atual Carta Magna de 1988, que trouxe enorme evolução em matéria trabalhista, trazendo princípios e normas que protegem e garantem a dignidade do trabalhador. Reafirma esse entendimento a lição consagrada por Nascimento (2011, p. 107) ao tratar do marco que representa a Carta Magna de 1988 para o direito trabalhista brasileiro:

[...], mas entendo que o período contemporâneo começa com a Constituição de 1988 embora algumas leis desse período possam ter vindo de antes, mas com ele se coadunam. Não é possível recusar o marco que representa no desenvolvimento do nosso direito do trabalho, como decorrência do processo político favorável à democratização do País, a Assembleia Nacional Constituinte 


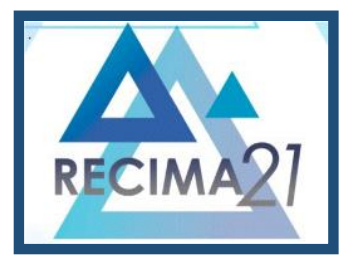

\title{
RECIMA21 - REVISTA CIENTÍFICA MULTIDISCIPLINAR ISSN 2675-6218
}

FLEXIBILIZAÇ̃̃ DAS LEIS TRABALHISTAS: OS ENTRAVES E DESAFIOS CONSTITUCIONAIS Abnoan Reis Santos Junior, Lucas Monteiro Mendes Batista, Marcus Vinicius do Nascimento Lima

que aprovou, em 5 de outubro de 1988, uma nova Constituição Federal, que modificou, em alguns aspectos, o sistema jurídico de relações de trabalho.

Em virtude do exposto, percebe-se claramente que o direto do trabalho é fruto de imensas lutas e processos enfrentados pelos trabalhadores. Um grande processo foi enfrentado até que se chegasse à legislação trabalhista atual, tanto em sede internacional quanto nacional. Diante disso deve se atentar para a tutela das garantias e direitos que são advindos de um longo e árduo caminho de conflitos e conquistas pelos trabalhadores.

\section{A NECESSIDADE DE ADAPTAÇÃO DAS LEIS TRABALHISTAS POR MEIO DA FLEXIBILIZAÇÃO}

O estudo da evolução histórica do direito trabalhista passa necessariamente pela compreensão do fenômeno da flexibilização normativa como sendo uma das características mais presentes nessa área da ciência jurídica. Tal característica se revela como uma consequência da ligação existente entre as normas trabalhistas e a realidade social do trabalho que se encontra em constante mudança. Desta forma, este capítulo propõe-se a analisar a necessidade de adaptação das normas trabalhista por meio da flexibilização.

A rigidez constante nas normas trabalhistas tradicionais passou a ser motivo de vários questionamentos acerca de sua eficácia nas últimas décadas, em um movimento impulsionado principalmente pela globalização e todas as suas consequências na dinâmica das relações de trabalho. Consoante a esse entendimento é a lição de Paulo e Alexandrino (2010, p. 6):

\begin{abstract}
Há alguns anos, entretanto, especialmente a partir do final da década de 80 e do início da de 90, vem sendo operada uma revisão, uma reavaliação, dos fundamentos e da utilidade de alguns dos direitos trabalhistas tradicionalmente constantes dos ordenamentos jurídicos dos países do Ocidente. Têm sido questionados, inclusive, os reais efeitos que a inserção de uma série de direitos rígidos no ordenamento jurídico produz sobre o mercado real de trabalho e a possibilidade ou o benefício da manutenção desses direitos em um mundo globalizado, marcado pela competição entre as empresas em âmbito internacional.
\end{abstract}

No mesmo sentido, complementam o estudo acerca desse fenômeno, as palavras de Cairo $\operatorname{Jr}(2017$, p. 129):

\begin{abstract}
Esse fenômeno, consubstanciado na terceira mudança radical no regime de trabalho, foi batizado de flexibilização, decorrente da realidade política atual do neoliberalismo, que pretende conferir efeitos plenos à autonomia da vontade privada de patrões e empregados por intermédio de atos praticados por si próprios ou representados por entidade sindical.
\end{abstract}

Uma vez que o direito do trabalho é o principal ramo da ciência jurídica a sofrer grande influência das mudanças observadas nas áreas econômica, social e política (LEITE, 2019), resta evidente a necessidade de compreender como necessária a adaptação das normas laborais, uma 


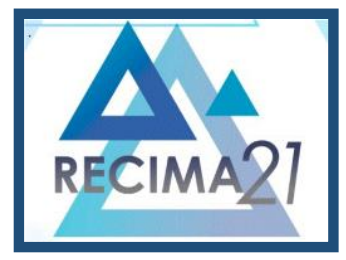

\section{RECIMA21 - REVISTA CIENTÍFICA MULTIDISCIPLINAR ISSN 2675-6218}

vez que o dinamismo que rege as relações de trabalho impõe à legislação trabalhista o desafio de conciliar a tutela da figura do empregado com as novas situações fáticas.

Da análise do posicionamento doutrinário acerca do tema conclui-se que o fenômeno da flexibilização normativa no direito laboral não se apresenta como um tema pacífico na doutrina, sendo evidenciado o surgimento de correntes doutrinárias que tratam sobre a necessidade de adaptação normativa no direito trabalhista. Assim, em síntese, três serão os principais posicionamentos adotados pelos autores que tratam sobre a flexibilização no direito laboral:

a) Corrente flexibilista: Trata-se da corrente que defende que a necessidade de as normas trabalhistas serem flexíveis, pois, segundo os seus adeptos, principalmente através da adaptação do direito trabalhista, seria possível alcançar melhores condições de desenvolvimento econômico e por consequência maior desenvolvimento social.

b) Corrente semiflexibilista: Trata-se de uma corrente conciliadora que, ao passo que reconhece a existência de uma parte da norma passível de flexibilização, defende a tutela de uma outra parte que não se sujeita a modificações, sob o argumento de que esta busca garantir as condições e garantias básicas necessárias ao trabalhador em sede da relação trabalhista.

c) Corrente antiflexibilista: Trata-se da corrente que defende a não flexibilização do direito trabalhista sob o argumento de que este instituto se traduz na perda de direitos sociais historicamente adquiridos pelos trabalhadores.

Apesar das divergências doutrinárias, cabe ainda trazer o preciso ensinamento de Leite (2019, p. 540)" a realidade fática dos últimos 20 anos é muito diferente daquela vivida no ano de 1940, quando foi promulgada a CLT". Dessa forma, resta evidenciada a notória problemática instaurada ao tentar aplicar uma legislação do século passado para regulamentar relações trabalhistas atuais, visto que esta não está preparada para prever todas as diversas inovações decorrentes dos contratos de trabalho firmados atualmente.

Em consonância com esse entendimento é outra lição de Alexandrino e Paulo (2010, p. 7):

Todos reconhecem, considerando a realidade atual, estar a CLT muito ultrapassada. Muitos de seus dispositivos acarretam engessamento das negociações entre empresas e empregadores, o que, como explicamos no início desse ponto, ao invés de facilitar, termina dificultando a contratação pelas empresas, resultando em desemprego ou em aumento do trabalho informal. Por esse motivo, nos últimos tempos, tem sido frequente a legislação ordinária buscar a introdução, em nosso ordenamento, de novos institutos trabalhistas, sempre no intuito de flexibilizar os contratos de trabalho, como são exemplo as leis do trabalho temporário, do trabalho a tempo parcial, da possibilidade de suspensão do contrato de trabalho etc.

Assim, a flexibilização normativa vigente no direito trabalhista brasileiro pode ser compreendida como um processo influenciado, parcialmente, pelo atraso presente na legislação pátria acerca das relações de trabalho, que encontra respaldo na Consolidação das Leis Trabalhistas. Nesse sentido, destaca-se a promulgação da Lei 13.467 de 2017, que instituiu a 


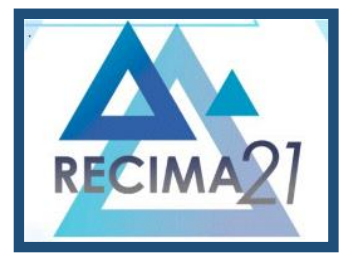

\title{
RECIMA21 - REVISTA CIENTÍFICA MULTIDISCIPLINAR ISSN 2675-6218
}

reforma trabalhista promovendo mudanças substanciais à CLT, que restam atestadas conforme Delgado e Delgado (2017, p. 255) "De fato, a flexibilização trabalhista pela via coletiva negociada é urna das marcas e sentidos dominantes da Lei n. 13.467/2017".

Ademais, nota-se que a flexibilização das normas trabalhistas é tema tão presente no contexto jurídico, econômico e social contemporâneo, que até mesmo o legislador constitucional se encarregou de prever situações que configuram esse fenômeno inclusas no próprio texto da Constituição Federal de 1988. É o caso do art. $7^{\circ}$, inciso VI que dispõe "irredutibilidade do salário, salvo o disposto em convenção ou acordo coletivo; inciso XIII que dispõe "duração do trabalho normal não superior a oito horas diárias e quarenta e quatro semanais, facultada a compensação de horários e a redução da jornada, mediante acordo ou convenção coletiva de trabalho"; e inciso XIV que dispõe "jornada de seis horas para o trabalho realizado em turnos ininterruptos de revezamento, salvo negociação coletiva".

O tratamento constitucional dado à flexibilização foi acertadamente definido nas palavras de Martinez (2019, p. 167):

\footnotetext{
A despeito dessas ponderações, um fato é inquestionável: a Constituição criou, sim, um sistema protetivo de direitos sociais e trabalhistas mínimos; autorizou, porém, em contraponto, fosse operada a flexibilização do referido sistema, mediante negociação coletiva, sobre assuntos que dissessem respeito a salários e a jornada (os dois mais importantes conteúdos do contrato de emprego).
}

Diante dessa realidade de permissão à flexibilização trazida pela Carta Magna de 1988 , Garcia (2017) aponta para o surgimento de discussões acerca da sustentação da criação de um novo princípio a ser incorporado no rol daqueles que regem o direito do trabalho, trata-se do princípio da flexibilização no direito trabalhista, ancorado nas disposições do próprio texto constitucional.

No entanto, a admissão deste princípio é controversa, conforme consagrado pelo autor supracitado, Garcia (2017, p. 65):

\begin{abstract}
A flexibilização, in pejus, de direitos trabalhistas, mesmo por meio de negociação coletiva, ainda que admitida pela Constituição Federal de 1988, é verdadeira exceção no sistema jurídico. Portanto, jamais é possível concluir que integra os fundamentos, ou seja, a estrutura e a essência do Direito do Trabalho. Sendo assim, não há como admitir status de princípio jurídico à flexibilização.
\end{abstract}

Portanto, a partir da análise do que fora exposto, restaram demonstradas de forma sucinta as principais razões que explicam a adoção do instituto da flexibilização das leis trabalhista no Brasil bem como sua razão e necessidade de existir vez que este instituto enfrenta atualmente 0 desafio de estabelecer a ponderação entre garantir a tutela histórica adquirida pelo trabalhador ao passo que assegura que as relações trabalhistas não sejam prejudicadas por uma legislação que não consegue acompanhar as novas dinâmicas do mercado de trabalho. 


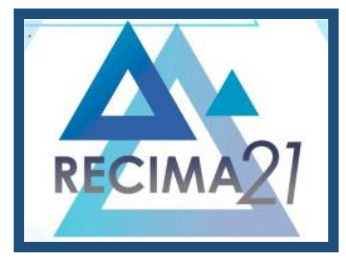

\title{
RECIMA21 - REVISTA CIENTÍFICA MULTIDISCIPLINAR ISSN 2675-6218
}

\section{FLEXIBILIZAÇÃO E DESREGULAMENTAÇÃO}

É muito comum que durante o estudo da flexibilização das normas trabalhistas, surjam dois conceitos que podem ser causa de muitas dúvidas, devido às suas aparentes semelhanças: flexibilização e desregulamentação. Segundo Delgado (2017, p. 67) "Na caracterização contemporânea do Direito do Trabalho despontam usualmente dois temas correlatos: a flexibilização e a desregulamentação trabalhistas". Assim, não é raro encontrar situações em que a flexibilização normativa é utilizada como um termo alternativo em referência à uma situação de desregulamentação, desta forma, faz-se necessária a análise e diferenciação de ambos os institutos, que serão abordadas nesse capítulo.

Inicialmente, destaca-se que a flexibilização no direito laboral, pode ser conceituada como a tentativa de promover uma adaptação da norma, aqui entendida como lei em sentido amplo bem como os princípios, com objetivo de torná-la menos imperiosa, podendo admitir novas situações fáticas, inclusive muitas delas estabelecidas por meio de acordo individual ou coletivo de trabalho, e que outrora sofreriam algum tipo de limitação legal.

Segundo as lições de Delgado (2017, p. 67), a flexibilização conceitua-se como:

\begin{abstract}
Por flexibilização trabalhista entende-se a possibilidade jurídica, estipulada por norma estatal ou por norma coletiva negociada, de atenuação da força imperativa das normas componentes do Direito do Trabalho, de modo a mitigar a amplitude de seus comandos e/ou os parâmetros próprios para a sua incidência. Ou seja, trata-se da diminuição da imperatividade das normas jus trabalhistas ou da amplitude de seus efeitos, em conformidade com autorização fixada por norma heterônoma estatal ou por norma coletiva negociada.
\end{abstract}

Já pelo entendimento consagrado por Leite (2019, p. 541) a flexibilização pode ser delimitada como "Trata-se de um processo de quebra da rigidez das normas, tendo por objetivo, segundo seus defensores, conciliar a fonte autônoma com a fonte heterônoma do direito do trabalho, preservando, com isso, a saúde da empresa e a continuidade do emprego".

Assim, a compreensão do instituto da flexibilização passa pela noção de que este pode assumir uma natureza muito ampla, assumindo diferentes efeitos, visto que embora seja aplicada majoritariamente com objetivo de promover uma simples releitura da norma em vista de mudanças impostas por um novo contexto social, econômico ou político, por outro lado pode também ser observado a eliminação de direitos previamente assegurados ao trabalhador como uma consequência da nova disposição normativa.

Por seu turno, a desregulamentação no direito laboral trata-se do instituto que se traduz na extinção, em partes ou no todo, da norma trabalhista, consequentemente promovendo o afastamento da tutela estatal sobre a situação regulada anteriormente. Dessa forma, observa-se que na promoção da desregulamentação o Estado acaba por garantir uma maior autonomia para a vontade das partes, dando liberdade para que haja deliberações acerca de determinado tema ou situação que outrora restava passível de intervenção estatal. 


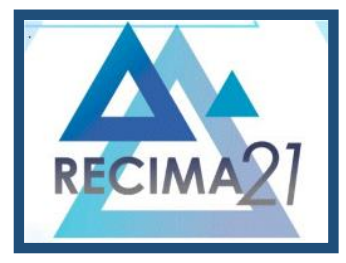

\section{RECIMA21 - REVISTA CIENTÍFICA MULTIDISCIPLINAR ISSN 2675-6218}

Em linha com esse entendimento são as lições de Delgado (2017, p. 70), ao estabelecer que a desregulamentação pode ser entendida como: "A desregulamentação trabalhista consiste na retirada, por lei, do manto normativo trabalhista clássico sobre determinada relação socioeconômica ou segmento das relações de trabalho, de maneira a permitir o império de outro tipo de regência normativa".

Já para Garcia (2017, p. 64) a definição de desregulamentação é:

A desregulamentação, por sua vez, refere-se ao fenômeno de suprimir determinadas normas jurídicas, principalmente estatais, pertinentes à regulação das relações de trabalho, passando os próprios atores sociais a estabelecer a regra aplicável. Nesse sentido, fala-se em desregulamentação negociada do Direito do Trabalho.

Finalmente, conclui-se que a diferença essencial que resta observada após a análise dos dois institutos, é traduzida nas palavras de Delgado "Nessa medida, a ideia de desregulamentação é mais extremada do que a ideia de flexibilização, pretendendo afastar a incidência do Direito do Trabalho sobre certas relações socioeconômicas de prestação de labor" (DELGADO, 2017).

Portanto, ainda que sejam institutos jurídicos resultantes de uma mesma circunstância, qual seja, a adaptação da norma trabalhista aos novos paradigmas sociais, econômicos e políticos, é evidente que após a apropriada análise de ambos reste afastada a aparente confusão que se verifica acerca do uso desses institutos como forma de definir uma mesma situação jurídica.

\section{OS DESAFIOS E ENTRAVES APRESENTADOS PELA CONSTITUIÇÃO Às FLEXIBILIZAÇÕES DA LEGISLAÇÃO TRABALHISTA}

Ao se falar em flexibilização é imperioso consignar que o direito ao trabalho, por força do art. 6o da Constituição Federal de 1988, é um direito social fundamental, assim sendo, deve-se proceder com cautela haja vista que existem certas características do direito do trabalho, isto é, algumas garantias e direitos assegurados ao trabalhador que devem permanecer imutáveis, para que não se reduza a condição do trabalhador a uma situação indigna, desumana e penosa.

Também se faz oportuno destacar que a flexibilização das normas trabalhistas é uma tendência, cujas discussões são amplificadas pelo contexto atual, tendo em vista os desafios trazidos diante de uma pandemia e a sua implicância na economia nacional e mundial. Em cenários de crise como este, é que surge a importância do expresso no presente estudo, reforçando o objetivo da Lex Fundamentalis em conciliar a permissão à ocorrência de tal fenômeno com a proteção e valorização do trabalho e da pessoa do trabalhador. Nesse sentido, este último e principal capítulo busca demonstrar quais os principais limites impostos pela Constituição Federal de 1988 à flexibilização da legislação trabalhista. 


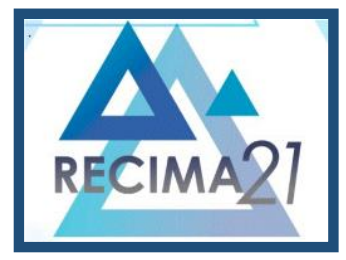

\title{
RECIMA21 - REVISTA CIENTÍFICA MULTIDISCIPLINAR ISSN 2675-6218
}

Inicialmente, resta evidente que os princípios, garantias e previsões de ordem constitucional que protegem a classe trabalhadora, visam sobretudo diminuir a desigualdade nas relações trabalhistas. A finalidade é amparar o trabalhador, reconhecido como polo mais frágil da relação. Diante disso, a flexibilização que desrespeite as normas constitucionais é entendida como uma espécie de "risco", uma vez que, caso não seja ponderado o que se pretende flexibilizar este fenômeno pode se tornar extremamente prejudicial ao trabalhador.

Assim, conforme já explicado no presente estudo, a Constituição não veda a flexibilização, no entanto o seu texto traz uma espécie de "sistema de freios" em sede de flexibilização, uma vez que há previsão do que pode ser objeto de flexibilização bem como prevê as formas em que esta deve ocorrer. É imperioso ainda atentar para a presença de limitações trazidas pela interpretação e aplicação de princípios constitucionais, uma vez que, assim como a norma em si, tal flexibilização também não poderá violá-los.

Ao dispor sobre o que pode ou não ser flexibilizado, a Constituição acabar por criar uma divisão entre os direitos trabalhistas absolutamente indisponíveis e os disponíveis, isto é, passiveis de flexibilização. Sendo assim, deve-se obedecer a razoabilidade e proporcionalidade de forma a não tornar o trabalho indigno e, por conseguinte resguardando a condição básica do trabalhador. Consoante ao exposto são as lições de Vecchi (2007, p208):

\begin{abstract}
A interpretação restritiva parece a mais razoável se levarmos em conta o todo constitucional. Assim, mesmo para hipóteses de flexibilização expressamente previstas na CF de 1988, não se está dando uma carta em branco para a restrição, pois qualquer restrição a um direito fundamental sempre deverá passar pelos critérios de razoabilidade, proporcionalidade e preservação do núcleo essencial dos direitos restringidos.
\end{abstract}

Nesse sentido, a primeira e principal forma de limitação à flexibilização da legislação trabalhista figura como um verdadeiro "alicerce" em matéria constitucional: o Princípio da dignidade da pessoa humana. Tal princípio figura como um dos fundamentos da República Federativa do Brasil, positivado no art. 1ํㅜㄹ inciso III da Carta Magna de 1988, e sua posição pode ser entendida, nas palavras de Sarlet (2012, p.81):

Importa considerar, neste contexto, que, na condição de princípio fundamental, a dignidade da pessoa humana constitui valor-guia não apenas dos direitos fundamentais, mas de toda a ordem constitucional, razão pela qual se justifica plenamente sua caracterização como princípio constitucional de maior hierarquia axiológico-valorativa[...]

Já para Silva (2014, p. 107) este princípio se traduz brevemente como: "Dignidade da pessoa humana é um valor supremo que atrai o conteúdo de todos os direitos fundamentais do homem, desde o direito à vida". Por consequência, ao ser aplicado no âmbito do direito laboral, o referido princípio busca estabelecer que sejam respeitadas as condições mínimas existenciais à pessoa do trabalhador, bem como ao regular exercício de seu trabalho. 


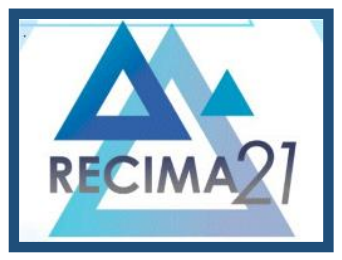

\title{
RECIMA21 - REVISTA CIENTÍFICA MULTIDISCIPLINAR ISSN 2675-6218
}

A segunda forma de limitação à flexibilização normativa reside na vedação ao retrocesso social, produto do Estado Democrático de Direito instituído pela Carta Magna. Assim, a partir da concepção, do direito do trabalho como um conjunto de normas de caráter social se torna nítido que não serão admitidas mudanças in pejus ou aquelas que, de alguma forma, tragam insegurança jurídica no âmbito dos direitos e garantias que consagram a tutela do trabalhador nas suas relações de trabalho.

Acerca da vedação ao retrocesso social, corrobora com o entendimento exposto anteriormente as precisas lições de Sarlet (2012, p. 411):

\begin{abstract}
Além do mais, tendo em conta que a dignidade da pessoa humana e a correlata noção de mínimo existencial, a despeito de sua transcendental e decisiva relevância, não são os únicos critérios a serem considerados no âmbito da aplicação do princípio da proibição de retrocesso, importa relembrar aqui as noções de segurança jurídica e proteção da confiança[...]Assim - mesmo que não se vá desenvolver estes aspectos - é certo que também na esfera da proibição de retrocesso tal como versada, a noção de segurança jurídica pressupõe a confiança na estabilidade de uma situação legal atual[...]Com efeito, a partir do princípio da proteção da confiança, eventual intervenção restritiva no âmbito de posições jurídicas sociais exige, portanto, uma ponderação (hierarquização) entre a agressão (dano) provocada pela lei restritiva à confiança individual e a importância do objetivo almejado pelo legislador para o bem da coletividade.
\end{abstract}

Como uma terceira forma de limitação, o texto constitucional traz em seu art. $1^{\circ}$, inciso IV o valor social do trabalho como um dos fundamentos da República, portanto, a ser estritamente respeitado pois, segundo Moraes (2014, p. 49) "é através do trabalho que o homem garante sua subsistência e o crescimento do país, prevendo a Constituição, em diversas passagens, a liberdade, o respeito e a dignidade ao trabalhador[...]". Trata-se de uma diretriz extremamente relevante no âmbito das relações trabalhistas, uma vez que o trabalho assume papel central na promoção da inclusão social, efetiva a distribuição de renda e funciona como meio de desenvolvimento social, econômico e cultural do homem. Assim, a Carta Magna de 1988 tratou de reconhecer o valor social do trabalho e por consequência atestar os princípios, regras e institutos que garantem a efetiva aplicação da legislação trabalhista.

A quarta forma de limitação consiste na observação das disposições que atestam a adoção do regime da Justiça Social no ordenamento jurídico brasileiro. Tal regime parte da conjunção entre a disposição, na Constituição Federal de 1988, do art. 170 caput, que estabelece os fundamentos e fins da ordem econômica e art. 193 caput, que traz como um dos objetivos da ordem social a justiça social:

Art. 170. A ordem econômica, fundada na valorização do trabalho humano e na livre iniciativa, tem por fim assegurar a todos existências dignas, conforme os ditames da justiça social, observados os seguintes princípios:

Art. 193. A ordem social tem como base o primado do trabalho, e como objetivo o bem-estar e a justiça sociais. 


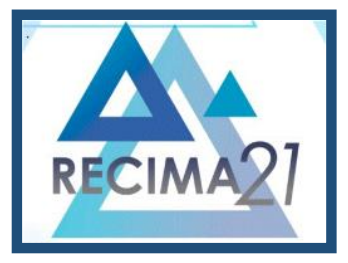

\section{RECIMA21 - REVISTA CIENTÍFICA MULTIDISCIPLINAR ISSN 2675-6218}

Reforça esse entendimento, o comentário de Silva (2014 p. 107) que ao tratar sobre ordem econômica e social assevera que: "Daí decorre que a ordem econômica há de ter por fim assegurar a todos existências dignas (art. 170), a ordem social visará a realização da justiça social (art. 193) [...]".

Deste modo, a justiça social se revela, em síntese, como um conjunto de orientações de cunho moral e político, que reconhecem as desigualdades sociais, culturais e econômicas existentes entre os seres humanos e diante dessa realidade busca conferir meios para que seus efeitos sejam atenuados. Logo, a consequência da adoção desse regime é a noção de um crescimento econômico que busque respeitar os direitos sociais e sua construção ao longo do tempo, servindo como meio de resguardar, entre outros, a proteção conferida ao trabalhador contra normas, disposições ou atos que venham a atacar sua esfera de direitos mínimos.

Impende ainda ressaltar a existência de uma quinta forma de limitação em virtude de tratados internacionais que versem sobre direitos humanos, equiparados a emenda constitucional, portanto, hierarquicamente superior e passíveis de servirem como instrumento de oposição às leis ou outros atos normativos, por força do art. $5^{\circ}$, $\S \S 2^{0}$ e $3^{\circ}$ da Constituição Federal. Por conseguinte, o conteúdo constante nos tratados que versem sobre direito do trabalho, conhecidamente classificado como um dos direitos humanos fundamentais, caso sejam aprovados conforme o procedimento disposto no art. 5, $\S 3^{\circ}$ da Constituição, em última análise poderão figurar como fatores limitantes diante de propostas legais de flexibilização da legislação trabalhista constante em norma infraconstitucional.

Por fim, em virtude do exposto é evidente que a Constituição de 1988 tratou de certificar o respeito aos princípios e fundamentos que tutelam e promovem a valorização do trabalho e da classe trabalhadora, com objetivo principal de evitar situação de lesão à segurança jurídica constitucionalmente priorizada em sede das relações de trabalho.

\section{CONCLUSÃo}

Conforme todo o exposto no presente estudo, constata-se que o instituto da flexibilização das leis trabalhistas surgiu como uma resposta ao incessante dinamismo que integra as relações de trabalho, aspecto que, conforme fora demonstrado, se mostrou cada vez mais relevante desde o final das décadas de 1980 e 1990.

No entanto, a partir do reconhecimento da construção histórica dos direitos trabalhistas através de um árduo processo de conflitos, bem como da importância do trabalho como meio de assegurar a dignidade humana, reputa-se obrigatória à observação de direitos mínimos conferidos aos trabalhadores, que formam uma espécie de núcleo mínimo e inafastável de garantias, tuteladas pelo ordenamento jurídico, em especial, pela norma constitucional.

Nesse sentido, restou demonstrado que a Constituição Federal de 1988 trouxe um verdadeiro sistema de tutela em sede de relação trabalhista, destacando-se o papel do Princípio 


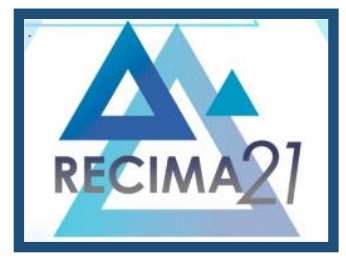

\section{RECIMA21 - REVISTA CIENTÍFICA MULTIDISCIPLINAR ISSN 2675-6218}

da dignidade da pessoa humana, do valor social atribuído ao trabalho, da proibição ao retrocesso social e da concretização da justiça social, sem prejuízo ainda do reconhecimento dos conteúdos de tratados internacionais que versem sobre direito laboral, como os principais fatores limitadores de propostas que tendem a flexibilizar a legislação trabalhista.

Portanto, conclui-se que a reforma da legislação que eventualmente venha a afetar a pessoa do trabalhador em sede de suas relações jus trabalhistas, deverá ser confrontada frente aos sistema de limites estabelecidos pela Constituição, somente sendo admitida sua integração ao ordenamento jurídico após demonstrada que há a devida ponderação entre prejuízos e benefícios que dela resultem e que, principalmente, tenha sido demonstrado a devida observância aos fundamentos e princípios da Lex Fundamentalis.

\section{REFERÊNCIAS}

BRASIL. Constituição República Federativa do Brasil de 1988. Brasília, DF: Senado Federal, 1988. Disponível em: http://www.planalto.gov.br/ccivil 03/constituicao/constituicao.htm.. Acesso em: 21 out. 2020.

CAIRO JR, José. Curso de Direito do Trabalho. 13. ed. Salvador: JusPodivm, 2017. 1392 p. ISBN 978-85-442-1342-1. Disponível em: https://docero.com.br/doc/xxeece. Acesso em: 22 out. 2020.

DELGADO, Mauricio Godinho. Curso de Direito do Trabalho. 16. ed. São Paulo: LTr, 2017. 1697 p. ISBN 978-85-361-9148-5. Disponível em: https://docero.com.br/doc/xxeec1. Acesso em: 22 out. 2020.

DELGADO, Maurício Godinho; DELGADO, Gabriela Neves. A Reforma Trabalhista no Brasil: com os comentários à Lei n. 13.467/2017. São Paulo: LTr, 2017. 382 p. ISBN 978-85-361-9461-5. Disponível em: https://docero.com.br/doc/nn8015v. Acesso em: 22 out. 2020.

GARCIA, Gustavo Felipe Barbosa. Curso de Direito do Trabalho. 11. ed. Rio de Janeiro: Forense, 2017. 816 p. ISBN 978-85-309-7499-2. Disponível em: https://docero.com.br/doc/n01es5c. Acesso em: 22 out. 2020.

LEITE, Carlos Henrique Bezerra. Curso de Direito do Trabalho. 11. ed. São Paulo: Saraiva Educação, 2019. 1481 p. ISBN 9788553605767 . Disponível em: https://docero.com.br/doc/c8cccc. Acesso em: 22 out. 2020.

MARTINEZ, Luciano. Curso de Direito do Trabalho. 10. ed. São Paulo: Saraiva Educação, 2019. 2105 p. ISBN 9788553606221 . Disponível em: https://docero.com.br/doc/nnv8csc. Acesso em: 22 out. 2020.

MORAES, Alexandre de. Direito Constitucional. 30. ed. São Paulo: Atlas, 2014. ISBN 978-85224-8811-7. Disponível em: https://docero.com.br/doc/s08n5x. Acesso em: 25 abr. 2021.

PAULO, Vicente; ALEXANDRINO, Marcelo. Manual de Direito do Trabalho. 14. ed. São Paulo: MÉTODO, 2010. $551 \quad$ p. ISBN 978-85-309-3163-6. Disponível em: https://www.academia.edu/33213325/Manual de Direito do Trabalho Vicente Paulo e Marcelo Alexandrino. Acesso em: 22 out. 2020. 


\section{RECIMA21 - REVISTA CIENTÍFICA MULTIDISCIPLINAR ISSN 2675-6218}

FLEXIBILIZACÃO DAS LEIS TRABALHISTAS: OS ENTRAVES E DESAFIOS CONSTITUCIONAIS Abnoan Reis Santos Junior, Lucas Monteiro Mendes Batista, Marcus Vinicius do Nascimento Lima

ROMAR, Carla Teresa Martins. Direito do Trabalho esquematizado. 5. ed. São Paulo: Saraiva Educação, 2018. Disponível em: https://georgenunes.files.wordpress.com/2018/11/Direito-doTrabalho-Esquematizado-Carla-Tereza-Martins-Romar-2018.pdf. Acesso em: 19 abr. 2021.

SARLET, Ingo Wolfgang. A Eficácia dos Direitos Fundamentais: uma teoria geral dos direitos fundamentais na perspectiva constitucional. 11. ed. Porto Alegre: Livraria do Advogado Editora, 2012. ISBN 978-85-7348-789-3. Disponível em: https://docero.com.br/doc/xsxxsx1. Acesso em: 25 abr. 2021.

SILVA, José Afonso da. Curso de Direito Constitucional Positivo. 37. ed. São Paulo: Malheiros, 2014. ISBN 978-85-392-0213-3. Disponível em: https://docero.com.br/doc/xn50x5. Acesso em: 25 abr. 2021.

VECCHI, Ipojucan Demétrius. Noções de Direito do Trabalho: um enfoque constitucional. 2. ed. Passo Fundo: UPF, 2007. v. 1. 